\title{
Planes de desarrollo en el sector educativo en colombia
}

\author{
William Guzmán Baena \\ Departamento de Psicopedagogia
}

\begin{abstract}
"Nunca consideres el estudio como una obligación sino como una oportunidad para penetrar en el bello y maravilloso mundo del saber" Albert Einstein (1879-1955) cientifico alemán nacionalizado estadounidense.
\end{abstract}

Y a en 1918 el Presidente de los Estados Unidos Woodrow Wilson habia enunciado escuetamente la noción del "desarrrollo", por cierto tutelado, pero hasta la Segunda Guerra Mundial (1939-1945) se hablaba de la evolución de los países mas bien en términos de avance desde el "atraso", caracterizado por la "primitividad" y la miseria con sus penosas secuelas, hasta el "progreso", caracterizado por la "civilización" y la prosperidad que traía aparejado el bienestar. Sólo un puñado de paises, en su mayoría americanos del norte y europeos, se hallaban entonces en situación de progreso y, por lo general, se suponía que los demás países también irían llegando hasta tal estado. ¿Cómo habrían de hacer eso? Aparentemente lo harian de un modo providencial, tal vez lento pero presumiblemente natural e ineluctable. Les bastaria con "dejar pasar y dejar hacer" y, si acaso, empeñarse en imitar a los progresados ciegamente y al máximo posible. Aunque el colonialismo prevalecía ostensiblemente aún, no habia conciencia clara, ni menos admisión

${ }^{196}$ Thomas Woodrow Wilson Biografía 1913 pública, de que no pocas de las naciones que más habian progresado en el mundo lo habían hecho, en alguna medida, a expensas del atraso de las demás. Y tampoco se prestaba real atención a la opresora inequidad vigente dentro de cada país atrasado en desmedro de la mayoría de la población. ${ }^{196}$

Sólo cerca del final del primer quinquenio de la era post Hiroshima surgió con firmeza en el mundo la noción de "desarrollo" como sustituto de la de "progreso". Optar por el desarrollo significaba a la sazón no dejar librado el avance hacia la prosperidad y el bienestar al azar "leseferista" y limitarse a la inacción providencialista sino prever y organizar racionalmente la intervención estatal activa para lograr pronto el mejoramiento sustantivo de la economía con apoyo de la tecnología a fin de forjar el adelanto material.

Tal transición provino en gran parte de la experiencia ganada por los Estados Unidos de América, en los campos de batalla y en la vida civil de retaguardia, en aquella segunda contienda bélica mundial y en la postguerra inmediata con el aprendizaje cobrado por 
dicho país altamente "desarrollado" al auxiliar, financiera y técnicamente, a las naciones perdedoras - Alemania, Italia y Japón - en su proceso de reconstrucción y rehabilitación.

A fines de la década de 1940 el Gobierno de los Estados Unidos de América cobró conciencia de que los numerosos países "subdesarrollados" que habían sido miembros de la alianza contra los países que constituyeran el eje nazifascista que desató la guerra merecian un apoyo semejante al que ya estaba brindando a éstos. El Presidente Harry Truman anunció en 1949, en el cuarto punto de un discurso de catorce, la creación de un programa internacional de asistencia, técnica y financiera, para el desarrollo nacional que llegaria a conocerse como el del "Punto Cuarto". Y se estableció para ejecutarlo el organismo que ahora se conoce como Agencia de los Estados Unidos de América para el Desarrollo Internacional (USAID).

El programa proporcionaba a los gobiernos, incluyendo desde luego a los de Latinoamérica, apoyo para ampliación y mejoramiento de infraestructura de caminos, vivienda, electricidad, agua potable y alcantarillado. Por otra parte, estableció con dichos gobiernos servicios cooperativos de agricultura, salud y educación a partir del inicio de la década de 1950. Comprendiendo que la acción pro desarrollo en estos campos requería provocar por persuasión educativa cambios de conducta tanto en funcionarios como en beneficiarios, incluyó en cada uno de esos servicios sociales una unidad dedicada a la información de apuntalamiento a los fines del respectivo sector.

Y esta medida llegaría a constituir una de las raíces mayores de la actividad que sólo varios años después iría a conocerse como "comunicación para el desarrollo".
¿Cómo llegó a constituirse y a operar esa disciplina profesional en Latinoamérica? A gentil invitación de los organizadores del tercer congreso panamericano de comunicación, el autor del presente texto se empeñará en dar la más sucinta respuesta posible a esta interrogante mediante una descripción analítica, a manera de testimonio en visión panorámica de algo más de medio siglo, por parte de un actor y observador de ese proceso.

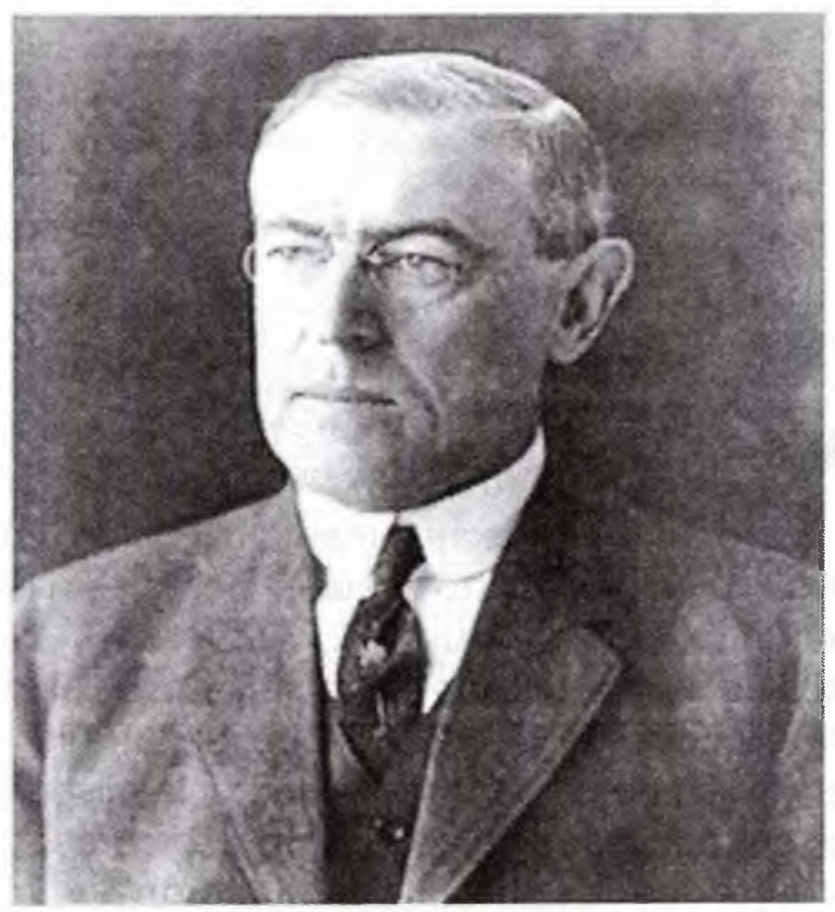

Thomas Woodrow Wilson (Staunton, 28 de diciembre de 1856 - Washington, D.C., 3 de febrero de 1924) fue el vigésimo octavo Presidente de los Estados Unidos. Llevó a cabo una política exterior intervencionista en Iberoamérica y neutral en la Gran Guerra hasta 1917. Su entrada en el bando denominado "Triple Entente" inclinó la victoria de este lado. En enero de 1918 expuso sus famosos catorce puntos para asegurar la paz en Europa y el mundo. Participó en la Conferencia de París y fue premio Nobel de la Paz en 1919 como impulsor de la Sociedad de Naciones.

Hijo del reverendo presbiteriano Joseph Ruggles Wilson y Janet Mary Woodrow. A pesar 
de padecer dislexia, consiguió graduarse en 1879 para entrar después en la Universidad de Virginia, donde estudió Derecho.

En enero de 1882, Wilson abrió un bufete de abogados en Atlanta, aunque esta experiencia no fue satisfactoria para él, teniendo en mente una futura carrera política. Así pues volvió a la Universidad para conseguir un Doctorado en Ciencias políticas por la Universidad Johns Hopkins. En 1902 fue escogido Presidente de la Universidad de Princeton, cargo que desarrolló hasta 1910.

En 1911 fue elegido Gobernador de Nueva Jersey por el Partido Demócrata, cargo que desarrolló hasta 1913. En 1912 consiguió ganar la nominación por el Partido Demócrata en las elecciones presidenciales de 1913 , elecciones que ganó, convirtiéndose en el $28^{\circ}$ presidente de los Estados Unidos.

Para un mejor consenso sobre los planes de desarrollo del sector educativo en Colombia, es conveniente tener una visión objetiva sobre el papel trascendental que han jugado en el desarrollo del país las diferentes misiones que nos han visitado.

\section{Misiones internacionales en Colombia 1930-} 1960

\section{Diagnósticos y recomendaciones}

\section{A) Misión Kemmerer}

En 1930 por invitación del presidente de ese entonces Dr. Enrique Olaya Herrera, fue visitado el país por la misión Kemmerer.

Aunque débil, la articulación de Colombia al mercado mundial permitió que en la economía nacional se manifestara la crisis internacional. A partir de 1929 se produjo una fuerte caída de las reservas internacionales; el desplome de los precios cafeteros (pasaron de 27,26 centavos de dólar en 1928 a 10,46 centavos en 1933) explica buena parte del descenso en las reservas, este mercado cubría cerca del $80 \%$ del total de exportaciones, por lo cual disminuyó considerablemente los ingresos por exportaciones. El otro rubro importante en la contracción de ingresos externos fue la suspensión del crédito, ocasionado por la crisis internacional y por la pérdida de confianza de los acreedores extranjeros en la capacidad de pago del país.

El descenso de los ingresos externos estuvo acompañado de una caída en las importaciones (de US $\$ 158,9$ en 1928 a US $\$ 44,7$ en 1933), que ocasionó un rudo golpe a la finanzas públicas, puesto que el aduanero era el principal ingreso del Estado (más del $60 \%$ del total de ingresos corrientes); esta circunstancia contribuyó a prolongar el déficit fiscal que se registraba desde 1926. Asi, el gobierno tuvo que enfrentar simultáneamente la interrupción de los flujos de crédito, la reducción de los ingresos aduaneros y los mayores pagos por la deuda externa adquirida durante los años de bonanza.

El resultado de este proceso fue una drástica recesión con caídas del PIB en 1930 y 1931. Este escenario determinó la paralización de las obras públicas y el descenso de la producción, con lo cual el desempleo estuvo al orden del día.

En este escenario llega al país la Misión Kemmerer con el propósito de ayudar a la estabilización de las condiciones económicas internas, conservando la adhesión al patrón oro. Esta visita se consideraba conveniente para aprovechar el concurso de técnicos de países con mayor experiencia administrativa que pudieran suministrar su consejo para la organización de las finanzas y el desarrollo económico y comercial colombiano. El espíritu de esta propuesta descansaba en la idea de seguir "una política de cooperación y no de litigio con el capital extranjero", tal como lo expresaba el recién electo presidente Olaya Herrera.

La misión habia sido contratada por primera vez 
durante la administración de Pedro Nel Ospina, con el objetivo de reformar el sistema financiero y fiscal. Esta misión llegó al país en marzo de 1923 y después de dos meses preșentó al gobierno nacional diez proyectos de Ley, de los cuales fueron aprobados los siguientes: Estatuto orgánico del Banco de la República, creación de la Superintendencia Bancaria y reglamentación de los bancos privados, formación del presupuesto nacional, fijación del número y nomenclatura de los ministerios, administración y recaudo de rentas nacionales, creación de la Contraloría General y reorganización de la contabilidad nacional organización del impuesto al papel sellado y timbre nacional y reglamentación de títulos negociables.

En agosto de 1930 llegó a Colombia, por segunda vez, la misión Kemmerer. Para ésta el mantenimiento del patrón oro era el eje del saneamiento económico; por ello, era indispensable que el banco central fuera prudente en la asignación del crédito y el control de la oferta monetaria, determinara un adecuado nivel de la tasa de redescuento y lograra un riguroso manejo de la cartera. Adicionalmente, era necesaria la obtención de presupuestos públicos equilibrados y la reorganización administrativa que permitiera un manejo técnico, ahorro en costos y mayor eficiencia en las funciones. Luego de dos meses de trabajo, la Misión de Consejeros presentó como resultado 17 proyectos de Ley, de estos 11 fueron puestos a consideración del Congreso, pero tan sólo 7 se convirtieron en leyes de la República:

Ley 57 de 1931 Reforma la Ley 45 de 1923 sobre establecimientos bancarios y a la 68 de 1924.

- Ley 73 de 1930 Sobre reservas oro y encaje bancario.

- Ley 82 de 1931 De reforma a la Ley 25 de 1923, orgánica del Banco de la República.
- Ley 79 de 1931 Código de Aduanas

- Ley 43 de 1931 Sobre administración y recaudación de rentas.

- Ley 81 de 1931 Reformas al impuesto sobre la renta.

- Ley 64 de 1931 Reforma a la Ley orgánica de presupuesto.

- Ley 30 de 1931 y decreto 2223 de diciembre 18/1931 Gravamen a la exportación de banano

Los proyectos que más atención recibieron en los debates fueron los relativos al manejo monetario, por ser quizá los que podían ofrecer una solución de corto plazo a los problemas económicos derivados de la crisis. De una parte, se procuraba aumentar la disponibilidad de dinero sin afectar la convertibilidad y de otra, balancear la participación de los accionistas en la Junta Directiva (quedó conformada por tres representantes del gobierno, dos por los accionistas de bancos colombianos, uno por los bancos extranjeros miembros, uno por las cámaras de comercio, uno por las asociaciones agrícolas departamentales y uno por la Federación Nacional de Cafeteros). ${ }^{197}$

Las reformas impositivas estaban orientadas a diseñar un cuerpo coherente de normas en las que se lograra la simplificación de procedimientos y la aplicación de métodos técnicos en la fijación de los tributos. En la parte organizativa se centralizó la administración, se vincularon como funcionarios del Estado a todos aquellos que ejercían algún cargo en la administración tributaria y se abandonó el sistema de fijación de impuestos hecho por las Juntas Municipales, que no contaban con suficientes conocimientos del tema y estaban sujetas a las influencias políticas.

El objetivo de contar con un presupuesto fiscal equilibrado tenía como requisito la existencia de

197Webber, Max- Economía y sociedad, sección obras de sociología, México FC 1974 
un código orgánico de presupuesto. La ley 64 de1931 otorgó mayores facultades al Ministerio de Hacienda para el manejo de la política fiscal, bajo la consideración de que a ese organismo le correspondía "el deber y la responsabilidad exclusiva de conservar el equilibrio del presupuesto".

El proyecto de impuesto a las exportaciones de banano fue el único de las propuestas puntuales hechas por la Misión que fue objeto de debate en el Congreso. Esta medida que proponía un impuesto de 2 centavos por racimo, sobre todo el banano exportado, generó una fuerte discusión con la United Fruit, que fue saldada con el cobro de 3 centavos por racimo pero con la promesa, hecha por el presidente, de no establecer más impuestos sobre este ramo en los siguientes veinte años.

Las otras propuestas hechas por la Misión de Consejeros se referían a la contabilidad, la Contraloría, la deuda pública y a más gravámenes, algunos de los cuales fueron implementados posteriormente.

Un comentario especial merece el problema de la deuda externa. De acuerdo con Paul Drake y Patino Roselli, la contratación de la misión Kemmerer estaba ligada al interés de brindar a los banqueros norteamericanos la seguridad de que Colombia estaba haciendo las reformas requeridas para sanear sus finanzas públicas, con miras a restablecer las condiciones crediticias. Similar diagnóstico se podia derivar de la opinión expresada por William Dunn, miembro de la misión: en su concepto los desórdenes reportados en varios países suramericanos fueron el motivo para que muchos inversionistas norteamericanos consideraran que no eran seguras las inversiones en bonos de estos países; para resarcir esa confianza era necesaria no solamente la estabilidad política (de la que Colombia era un ejemplo sobresaliente) sino también era preciso establecer los factores favorables o desfavorables al cumplimiento de los compromisos externos.

\section{B) LA MISION CURRIE (1960)}

En el período de la postguerra surgió como foco de inquietud económica a nivel internacional el problema del desarrollo. En la Carta del Atlántico, firmada por Inglaterra y Estados Unidos en agosto de 1941 -y suscrita por muchas naciones, entre ellas Colombia-, se planteaba la urgencia de adelantar medidas tendientes a mejorar el nivel de vida de la población para evitar que, en aras de mejores condiciones, ésta se inclinara por aceptar las ideas comunistas. En esta Carta también se proclama la autonomía de los pueblos, el multilateralismo comercial y la colaboración económica entre todas las naciones para asegurar mejores condiciones de trabajo, adelanto económico y seguridad social. Propuestas similares fueron adelantadas a partir de los organismos internacionales creados en esa época como la ONU y el BIRF.

En este ámbito se situaba el punto de arranque para que el Estado se interesara por impulsar y planear el desarrollo económico. La intensificación del proceso industrializador, la ampliación del mercado interno y el aumento de la población urbana, configuraban un escenario cambiante que permitía y esperaba la sistematización de los datos correspondientes a la nación, al estado de sus recursos y a las prioridades sobre las cuales debía descansar el progreso.

La historia del contrato que da lugar a la Misión Currie se inicia en 1948, cuando en Bogotá tiene lugar la Conferencia Panamericana y se desata la conmoción social conocida como el Bogotazo:"

Terminada la Conferencia el gobierno colombiano hace una solicitud de crédito al Banco Mundial por valor de US\$78 millones, 
destinado a obras de reconstrucción e inversiones varias (Fomento agrícola, irrigación, electrificación, ferrocarriles, carreteras y la iniciación de Paz del Río).

Las negociaciones no tuvieron éxito por cuanto esos organismos exigían como requisito para el desembolso el cumplimiento de los principios acordados en Bretton Woods y la corrección del desbalance externo. Los técnicos del FMI recomendaban la unificación y devaluación de la tasa de cambio, pero el gobierno colombiano se oponía a esta medida argumentando que la oferta cafetera no respondía a estímulos de corto plazo, mientras que los capitales si, por ello una devaluación no produciría sustanciales aumentos de las exportaciones cafeteras, pero si fuga de capitales; además podrian producirse presiones inflacionarias. Después de muchas discusiones, el Estado devaluó en 10\% la tasa de cambio, redujo el impuesto de giro y eliminó la prima cafetera (según el FMI esta era equivalente a tener una tasa de cambio preferencial). ${ }^{198}$

Con este antecedente, a finales de 1948 se inician las conversaciones entre John McCloy presidente del BIRF y Emilio Toro miembro de la junta de Directores Ejecutivos del mismo organismo, en torno a la concesión del empréstito. Frente a los reparos de McCloy sobre la falta de garantía de un adecuado uso de los recursos, se decidió el envío de una Misión del BIRF para que hiciera tal evaluación. Esta situación propició que por primera vez una misión de ese organismo tuviera que ver no sólo con proyectos específicos, sino con un amplio rango de tópicos incluyendo aspectos de política macroeconómica general y temas como salud, educación y administración.

En Mayo de 1949 se decidió el envío de la Misión, a cargo del profesor Currie. Esta Misión fue conformada por expertos en los diferentes campes que se iban a tratar y procedentes de distintas

Instituciones. El principal objetivo expresado por el Banco era el de enunciar las bases para un programa coherente y global de desarrollo, orientado a elevar el nivel de vida de la población. Al decir del Banco Mundial, el informe sólo sería plenamente efectivo si sirviera como guia para hacer un programa de desarrollo lógico y bien equilibrado y como medio para educar a la opinión pública.

Dentro del diagnóstico presentado por la Misión se destacaba el bajo nivel de vida de la población, reflejado en la falta de elementos básicos como salud, educación, vivienda y bienes y servicios. Pero estas deficiencias tenían solución, pues, provenian de la baja productividad ocasionada por factores distintos a la disponibilidad de recursos naturales; el problema fundamental se reducia a la asignación de recursos. Se trataba más bien de distribuir los fondos internos, ya que el capital extranjero se concebía como una ayuda deseable y no como un requisito para el desarrollo. Los recursos a reubicar eran especialmente la fuerza de trabajo y el capital: en el primero había que propiciar una distribución poblacional mayoritariamente urbana; en el segundo era preciso sustituir la importación de algunos bienes para que con el ahorro que de ello se hiciera pudiera incrementarse la inversión de capital.

El estudio se desarrolló por ramas de la actividad económica e incluyó los elementos que competen a la política económica. Teniendo en cuenta que el diagnóstico general es el bajo nivel de productividad, las medidas estaban orientadas a incrementarlo en los diferentes sectores.

\footnotetext{
${ }^{198} \mathrm{H}$ Jaramillo 1949 memoria de hacienda y crédito público, Bogotá Imprenta del banco de la república
} 
En el sector agricola la estrategia tenía varios componentes: a) fiscal, creado para estimular la utilización eficiente de la tierra, por medio del gravamen a los terrenos improductivos; $b$ ) planeación, a la que además se debía sumar la coordinación de los diversos programas que se adelantaran; c) productivo, en donde se proponía el reacomodamiento de la producción para que la explotación agricola se desarrollara en terrenos planos susceptibles de ser mecanizados y se abandonaran las explotaciones en zonas de ladera; $y \mathrm{~d}$ ) crediticio, en donde se ampliara la capacidad, pero estableciendo créditos condicionales.

En el ramo industrial se trataba de incrementar la eficiencia y reducir los costos, entre los cuales se encontraba la mano de obra: una mayor disponibilidad de trabajadores permitiria ajustar los salarios a las condiciones de eficiencia. Como puntos centrales para una estrategia del desarrollo, la Misión dedicó varios capítulos al problema del transporte, en sus diversas modalidades; y luego se ocupó de la salud, la educación, la higiene y los servicios públicos.

Es preciso destacar que uno de los llamados de atención más significativos fue sobre la importancia de contar con órganos de planeación, que permitieran fijar directrices de largo plazo y responder a las dificultades coyunturales.

Es preciso destacar que uno de los llamados de atención más significativos fue sobre la importancia de contar con órganos de planeación, que permitieran fijar directrices de largo plazo y responder a las dificultades coyunturales.

Para llevar a la práctica las recomendaciones de la Misión Currie se creó el Comité de Desarrollo Económico, por medio del Decreto 2838 del 1 de septiembre de 1950 . Este fue conformado por un grupo de ciudadanos sin compromiso político con el Estado, con el fin de evaluar dichas recomendaciones y darles la forma de Ley de la República.

Un pilar importante de la misión Currie fue el informe sobre la organización administrativa del país entregado en 1951. La misión era enviada como un complemento de las recomendaciones de la misión económica, pues las mejoras organizativas eran prerrequisito para lograr una producción y utilización eficiente de los recursos. La Misión se orientó a lograr que la estructura administrativa tuviera un diseño que le permitiera ser más eficaz, teniendo en cuenta que "sería utópico esperar que a través de cambios en la organización pudiera elevarse el nivel de eficiencia y honestidad en el Gobierno por encima del nivel de eficiencia y honestidad del país".

Esta percepción tendía a reforzar la postura que defendía la importancia de la intervención del Estado en la economía, que se oponía a lo que percibe la Misión en el pais, en donde "en un sector crecido de la población, hay una actitud cínica, casi derrotista, frente a las cosas del Gobierno y de la "política". Hay una sensación de frustración, de que nada puede hacerse y que el menor mal se logra restringiendo el papel del Gobierno en la medida de lo posible, distribuyendo al mismo tiempo el mayor número de actividades gubernamentales entre entidades semi-autónomas o completamente independientes". Contrario a esta posición Currie opinaba que era mejor la intervención, si ésta no obstruia la actividad privada y se desenvolvía de acuerdo con la planificación, entendida como la aplicación de un estudio intenso y técnico que permitiera revisar y ajustar las líneas de conducta de la Administración Pública.

\section{C) Misión CEPAL (Comisión Económica para la América Latina) (1954)}

En 1949, al poco tiempo de haberse creado la Cepal, el economista argentino Raúl Prebisch 
dio a conocer un informe en el que criticaba el viejo esquema de la división internacional del trabajo y señalaba a la industrialización como el único medio de que disponían los países subdesarrollados para captar una parte del progreso técnico y elevar progresivamente el nivel de vida de la población. Esa industrialización podía actuar simultáneamente con el crecimiento del comercio exterior y la exportación de materias primas; pero era necesaria la mayor afluencia de inversiones extranjeras, la integración entre las políticas monetaria y de desarrollo, la modificación de los patrones de consumo, para generar la creciente acumulación que el desarrollo requería.

En 1951, en un estudio elaborado por la Cepal para su cuarto periodo de sesiones, se insistió en la necesidad de modificar la estructura del comercio internacional y de promover una eficaz política de desarrollo, la cual debía ser fruto del esfuerzo propio. Se debía propender por la aceleración del ritmo de crecimiento, teniendo una mayor capitalización interna y más cuantiosas inversiones extranjeras, y haciendo uso del sistema impositivo para desalentar ciertos consumos, conseguir unmejor aprovechamiento de la tierra y estimular la capitalización. No obstante, este modelo general se percibía como sujeto a la realización de cuidadosos estudios. Estas tesis señalaban la necesidad de la planeación entendida como la aplicación de técnicas de programación orientadas a permitir que los mecanismos de mercado operaran con mayor eficacia.

En Caracas a principios de 1954 , en la X Conferencia Panamericana, en Brasil en la IV Reunión del Consejo Interamericano Económico y Social y en el Estudio Económico de la CEPAL, del mismo año, volvió a subrayarse la necesidad de una politica de desarrollo capaz de librar a Latinoamérica del atraso económico en un plazo razonable.
Atendiendo la necesidad de adelantar estudios sobre las condiciones para el desarrollo de los países de América Latina, la CEPAL organizó una serie de visitas a los países del hemisferio. A Colombia la misión llegó en marzo de 1954 , en el marco de los acuerdos sobre técnicas de programación aprobados en las sesiones de la CEPAL en 1953 -que dieron lugar a los estudios sobre Análisis y proyecciones del desarrollo.

En el pais se trabajó estrechamente con varias entidades gubernamentales, especialmente con el

Comité de Planeación Económica y Fiscal, se contócon la participación de la ANDI, que aportó personal técnico, y las universidades vincularon algunos de sus estudiantes. A pesar de ser un estudio metodológico, tenía la intensión de proveer conclusiones útiles a las autoridades económicas del país. Como uno de los resultados de esta misión se dejó un documento que debía servir como herramienta técnica para adelantar cálculos sobre el desempeño de la economía, es decir, cómo deberían establecerse el comportamiento de diferentes variables para lograr una determinada tasa de crecimiento. ${ }^{199}$

El documento presentó un balance global del desarrollo histórico de la economía colombiana y de las características de la situación de ese momento. En su primera parte entregó un análisis de la demanda de bienes y servicios de consumo, del sector externo y del crecimiento de la capacidad productiva. La segunda parte correspondió a los estudios sectoriales, principalmente agricultura, industria, energía, transporte y comunicación.

También se introdujo un análisis de la política fiscal y económica del sector público desde 1925 y un examen de las posibles necesidades futuras, teniendo como premisa la provisión de

199 SAMUELSON, Paul y NORDHAUS, William. Economía Mc Graw Hill 
capital y servicios sociales básicos por parte del Estado. Se entendía que la función de la política fiscal era influir favorablemente en el juego de las fuerzas que determinan el monto de recursos de acumulación; y su eficacia se debía evaluar en el impacto sobre el módulo ahorro-consumo, en lainfluencia para atraer recursos externos y en promover una mejora en la relación de precios de intercambio. Igualmente, se investigó el sistema financiero, tanto público como privado, en particular su influencia sobre el crédito dadas las necesidades de financiamiento de la inversión. El diagnóstico debía ser la base que brindara los antecedentes necesarios para adelantar las proyecciones.

El estudio fue entregado en 1955 y representa uno de los más completos que se han adelantado en Colombia y que aún hoy sirve de base documental cuando se va a estudiar la economía del período 1925-1953.

Para la proyección del crecimiento, la Misión construyó dos escenarios en los que el eje es la tasa esperada de crecimiento del PIB, y sobre esta base se establecieron los requisitos de consumo, inversión, balanza de pagos, financiación y balance del sector público. Entre las conclusiones del estudio se encuentra la urgencia de promover la sustitución de importaciones, adelantar medidas proteccionistas que la garanticen, una política fiscal redistributiva basada en la tributación directa y una mayor intervención del estado orientada a encauzar sumas importantes destinadas a inversiones que el capital privado no pudiera hacer.

Para finalizar sus labores en el país la Misión realizó tres cursos generales sobre desarrollo económico, aṕlicados al caso colombiano, los cuales fueron organizados en cooperación con la dirección ejecutiva del Comité Nacional de Planeación.

\section{D) La Misión LEBRET (1955)}

"La inteligencia solo aplasta. El amor solo es ineficaz. El amor de los hombres debe ser inteligente, laborioso y técnico". Louis Joseph Lebret

En 1954 a instancias de ÁlvaroOrtiz Lozano, director ejecutivo del Comité Nacional de Planeación (CNP), el presidente de la República pidió al Centro de Investigación Economía y Humanismo, instituto francés, que aplicara sus métodos de análisis en Colombia para determinar las potencialidades y la mejor forma de aprovechamiento de los recursos nacionales. En particular, el Estado quería conocer el nivel de vida de la población para establecer las necesidades de consumo y dotación; contar con un estudio de diagnóstico y perspectivas de la situación económica del pais para adelantar una planeación racional; y determinar las necesidades educativas.

La misión fue dirigida por el presbitero Louis Joseph Lebret, contó con la colaboración de los padres Birou (sociólogo) y Viau (especialista en pedagogía) y de los expertos Delprat (especialista en coyuntura) y Labasse (especialista financiero). Como representantes colombianos se encuentran: Beltrán (arquitecto urbanista), Morales (experto agricola) y como funcionarios del CNP están Nagy (economista, agrónomo) y Célestin, quien pertenecia al instituto economía y humanismo pero habia sido contratado como técnico por el CNP. ${ }^{200}$

La metodología utilizada por la Misión fue la encuesta sociológica, empleada como

200 Young. A. (1980) "Rendimientos crecientes y progreso económico". En revista planeación y desarrollo Volumen XII Bogotá departamento de planeación nacional. 
mecanismo pára preparar y orientar la acción y para favorecer una intervención en orden de urgencia. Su objetivo era permitir un conocimiento de la realidad humana, social y económica básica, necesario para establecer los grados y formas de intervención con miras a alcanzar el mejoramiento del nivel de vida del país.

Al respecto, se impone el estudio de las potencialidades y posibilidades teniendo en cuenta tanto las del suelo como las de las riquezas minerales y las posibilidades de energía y también los activos físicos agrícolas e industriales ya existentes, el nivel técnico alcanzado y la capacidad de ahorro y de inversión.

La originalidad del aporte, según la Misión, residía en la importancia que daban, por una parte, a la población, a sus niveles de vida y a sus necesidades, y por otra, al esfuerzo educativo requerido para un desarrollo económico y humano a la vez. Por estas razones hacía énfasis en los factores sociológicos que dentro de las nuevas orientaciones de los estudios económicos no podían separarse del análisis económico propiamente dicho. Esta Misión entendía su trabajo inserto en las perspectivas de una economía de necesidades, de desarrollo armonizado y de esfuerzo para realizar una civilización auténtica.

La pretensión, como la de la CEPAL, no era presentar un plan de desarrollo, sino elaborar un diagnóstico. Después de analizar las necesidades de la población y las posibilidades de satisfacerlas,se quería proponer un arbitraje o decisión entre los órdenes de importancia, las urgencias y las implantaciones para facilitar la tarea de los responsables económicos y políticos a quienes correspondía la decisión definitiva.

El trabajo entregado por esta misión se encuentra dividido en cinco partes: la primera se ocupa del nivel de vida y de las necesidades de la población colombiana; la segunda, de las potencialidades y las posibilidades físicas del país en relación con las necesidades; la tercera, de las potencialidades y posibilidades financieras; la cuarta, de los arbitrajes en función del desarrollo armonizado y la quinta del problema educativo.

Dentro de los elementos graves señalados en el informe Lebret, vale la pena destacar "el hábito de la población colombiana de admitir comportamientos antieconómicos: utilización casi totalmente irracional del suelo; persistencia de todas las rutinas que provocan la erosión y el desgaste de las tierras; afición irreflexiva y exagerada por productos extranjeros de los cuales se podría prescindir, o que fácilmente se podrían producir en el país; entusiasmo por grandes proyectos costosos, insuficientemente estudiados; anarquía de experiencias no preparadas y carentes de coordinación; escaso interés en la investigación científica basada en datos colombianos; complacencia en las oposiciones sin verdaderas ideologías y en las proyecciones irreales".

En opinión de Lebret, Colombia iría al fracaso si no efectuaba grandes cambios en las costumbres y en la mentalidad, si la orientación del desarrollo no se hacía con base en estudios continuados y precisos y no se adelantaba con una firmeza capaz de romper las resistencias atrasadas o egoístas.

\section{E) Misión CEPAL (1958)}

El BID en su balance de las reformas institucionales y del desarrollo en América Latina, señalaba que desde la última postguerra los países de este hemisferio fueron tomando conciencia de que el desarrollo no tendría una correcta orientación y equilibrio si no se destinaban recursos a programas de inversión social, que facilitaran la acción de una política de desarrollo económico y que permitieran 
incorporar al conjunto de la población en el crecimiento económico.

En los años cincuenta se afianzó la idea de que el panamericanismo debia ser algo más que una forma jurídica y que la vinculación de naciones no podría lograr si persistían las extremas desigualdades en los niveles económicos y sociales entre los países. Igualmente, fue ganando fuerza el reconocimiento de que la estructura institucional había permitido que el crecimiento diera lugar a la concentración del ingreso y de que, por lo tanto, era necesario impulsar reformas estructurales que permitieran dar mayor dinamismo y equidad distributiva al proceso de desarrollo. 201

Dentro de esta nueva concepción se realizó la reunión de Bogotá en septiembre de 1960, convocada por la OEA para estudiar la formulación de medidas de cooperación económica continental. Se determinó que los planes de desarrollo fueran complementados con medidas para hacer frente a las necesidades sociales y se estableció el Programa Interamericano de Desarrollo Social, orientado a que en los países se tomaran medidas que contribuyeran a mejorar las condiciones de vida de la población. Estados Unidos presentó la decisión de establecer el Fondo Especial Interamericano de Desarrollo (FID), el cual fue creado en mayo de 1961, a partir de los US $\$ 500$ millones aportados por ese pais, con los cuales se debia financiar los programas de reforma agraria, acueducto, vivienda, educación y adiestramiento avanzado en ramas relacionadas directamente con el desarrollo social.

En agosto de 1961 se llevó a cabo la reunión de Punta del Este, en donde se firmó la llamada

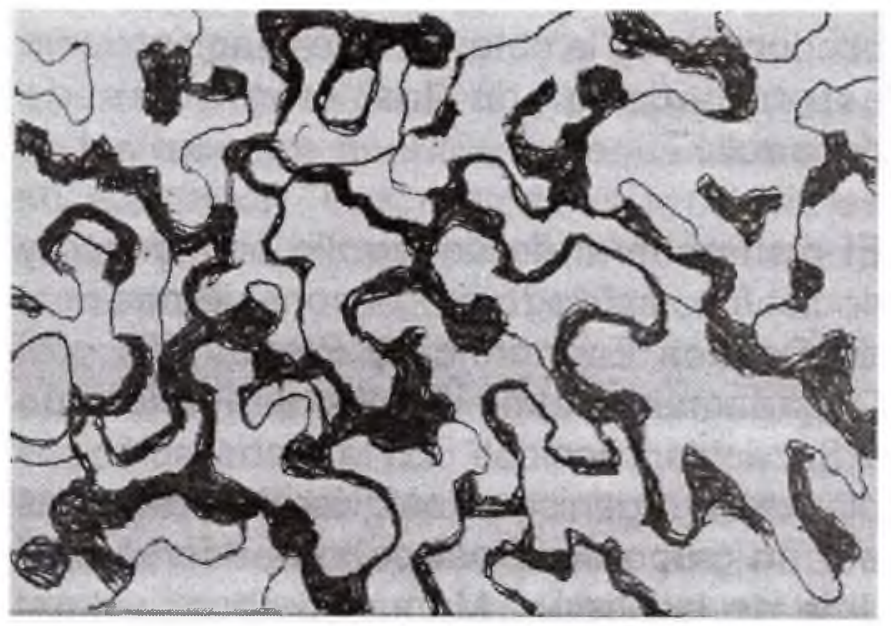

"Declaración a los pueblos de América" a través de la cual los paises signatarios se comprometían a "acelerar el desarrollo económico y social, a fin de conseguir un aumento sustancial y sostenido del ingreso por habitante, para acercar en el menor tiempo posible el nivel de vida de los países latinoamericanos al de los paises industrializados" .Entre los objetivos consagrados en esa Carta estaban: incrementar el ingreso por habitante en no menos de $2.5 \%$ anual, lograr una distribución equitativa del ingreso, avanzar en el proceso de diversificación económica nacional y reducir la dependencia respecto al comercio exterior, acelerar la industrialización y aumentar el nivel de empleo, elevar la productividad y la producción agrícolas, llevar a cabo una reforma agraria integral orientada a transformar los injustos sistemas de explotación y tenencia de la tierra, y mantener niveles de precios estables.

Colombia fue el primer país latinoamericano en presentar un plan de desarrollo económico y general a la evaluación de la nómina de los nueve, de acuerdo con lo establecido en Punta del Este, para cumplir con los trámites

\footnotetext{
201 Young. A. (1980) "Rendimientos crecientes y progreso económico". En revista planeación y desarrollo Volumen XII Bogotá departamento de planeación nacional.
} 
conducentes a la obtención de financiamiento externo global de los programas de desarrollo.

El plan general de desarrollo económico y social fue realizado por el consejo nacional de Política Económica y Planeación y el Departamento Administrativo de Planeación y Servicios Técnicos. En la elaboración del plan estos organismos estuvieron asesorados por un grupo de expertos, que además del Jefe de la Misión, Manuel Balboa, estaba compuesto por tres funcionarios de la CEPAL $y$ tres expertos contratados especialmente por el Departamento de Operaciones de Asistencia Técnica de las Naciones Unidas. Este plan tenía como objetivo establecer los niveles en los cuales debian situarse los diversos agregados económicos, para que el país obtuviera un aceptable ritmo de crecimiento económico.

De acuerdo con Balboa el propósito esencial del grupo asesor era colaborar con los funcionarios de planeación y de los Ministerios que se proponian mejorar el funcionamiento de una organización administrativa y técnica que elaborara de un modo permanente los estudios básicos necesarios para orientar la política de desarrollo económico del país. En sustancia era una misión para elevar el grado de capacitación de los funcionarios, de planear la realización de estudios económicos y de organizar entidades técnicas del gobierno. Esta labor se cumplía trabajando directamente con los funcionarios y formulando programas de desarrollo proyectos específicos de inversión.

El programa se fijó como meta una tasa de crecimiento de la producción de $5.6 \%$ anual, que sería la necesaria para que, dado un crecimiento del $3 \%$ anual de la población, se pudiera obtener una tasa de crecimiento de $2.6 \%$ per-cápita. Éste era el mínimo esfuerzo que proponía el programa de la Alianza para el Progreso, más abajo de este límite se encontraría la consolidación de la pobreza y la amenaza de la inestabilidad social, más arriba podía ser un esfuerzo desproporcionado, una exigencia inmoderada de ayuda exterior y una confianza excesiva en que los precios del café no se debilitaran mucho. El mayor esfuerzo debía hacerse, sin embargo, en el mantenimiento del equilibrio de la balanza de pagos, lo cual implicaba que se aumentaran vigorosamente nuevos renglones de exportación.

El problema del desarrollo nacional radicaba, entre otras cosas, en que no se podia considerar el incremento de las importaciones sin un previo aumento de las exportaciones; pero tampoco era concebible un incremento de la capacidad productiva interna y de la expansión de las exportaciones sin el incremento de las importaciones de bienes de capital e intermedios. Este círculo vicioso sólo podía romperse con una ayuda externa otorgada para la ejecución de un programa general, y en no pocos casos simplemente para mantener el equilibrio de la balanza de pagos. En Punta del Este se logró un avance en tanto se dijo que dicha ayuda financiera externa debía tomar la forma de subvenciones o préstamos de largo plazo y condiciones flexibles de pago, para que la balanza no se desequilibrara con el pago de la deuda en el momento mismo en que se necesitaba un mayor cupo de importaciones.

\section{Plan Nacional de Desarrollo de Colombia}

\section{1) Introducción}

El Plan Nacional Desarrollo es la base de las políticas gubernamentales de los presidentes de Colombia. El proceso electoral colombiano intenta ligar las propuestas de campaña de los aspirantes a la presidencia de la República con su gestión durante los cuatro 
años de gobierno. Para ello la Constitución y la Ley han ordenado la práctica de la planeación en Colombia. En tal sentido, la base del Plan, del presidente electo, son las propuestas de campaña presentadas ante la Registraduría Nacional del Estado Civil en el momento de su inscripción como candidato, conocidas como el programa de gobierno. Adicionalmente, dicho marco legal también vincula la participación de diversos sectores de la Sociedad Civil por medio del Consejo Nacional de Planeación para la elaboración del mismo. De esta manera el Plan Nacional de Desarrollo es el instrumento legal por medio del cual se dan a conocer los objetivos de gobierno del presidente de Colombia y su gestión, y además, permite evaluar sus resultados.

\section{2) Historia}

La práctica de la planeación fue establecida en Colombia a comienzos de los años 50 en el gobierno de Mariano Ospina Pérez, con el apoyo de una misión del Banco Mundial. En 1958 recibió un impulso con la creación del Departamento Nacional de Planeación.

La Constitución política de Colombia de 1991 en su artículo 339 del Título XII: "Del Régimen Económico y de la Hacienda Pública", Capítulo II: "De los planes de desarrollo", señala que:

Habrá un Plan Nacional de Desarrollo conformado por una parte general y un plan de inversiones de las entidades públicas del orden nacional. En la parte general se señalarán los propósitos y objetivos nacionales de largo plazo, las metas y prioridades de la acción estatal a mediano plazo y las estrategias y orientaciones generales de la política económica, social y ambiental que serán adoptadas por el gobierno. El plan de inversiones públicas contendrá los presupuestos plurianuales de los principales programas y proyectos de inversión pública nacional y la especificación de los recursos financieros requeridos para su ejecución. Las entidades territoriales elaborarán y adoptarán de manera concertada entre ellas y el gobierno nacional, planes de desarrollo, con el objeto de asegurar el uso eficiente de sus recursos y el desempeño adecuado de las funciones que les hayan sido asignadas por la Constitución y la ley. Los planes de las entidades territoriales estarán conformados por una parte estratégica y un plan de inversiones de mediano y corto plazo, (Art. 339 CPC 1991)

Este artículo constitucional fue reglamentado en la Ley 152 de 1994, durante el gobierno del presidente César Gaviria por la cual se estableció la Ley Orgánica del Plan de Desarrollo. Esta Ley extiende la práctica de la planeación a los demás entes territoriales. Asi, se puede hablar de Plan Territorial de Desarrollo, que puede ser Local (correspondiente a las localidades de Bogotá), Municipal, Distrital o Departamental; y el Plan Nacional de Desarrollo que a la presente es el nombre con que se conocen a los gobiernos de los distintos presidentes.

Se presentan los nombres de los presidentes su periodo y el nombre del plan de desarrollo. Referencia que se hace desde la administración del Dr. Misael Pastrana Borrero hasta la actual del Dr. Juan Manuel Santos. (ver cuadro siguiente)

\section{3) Consideraciones experimentales}

En el sector educativo, las orientaciones dejadas por las diferentes misiones fueron encaminadas a: efectuar reformas desde cambiar la denominación de varios términos pedagógicos, tales como el de maestro por el de educador, escuela por el de centro docente, sede o colegio, instituto por el de Institución Educativa ,etc. 


\section{PAIDEIa Surcolombiana 17}

\begin{tabular}{|c|c|c|}
\hline Presidente & Periodo & Plan de Desarrollo \\
\hline Misael Pastrana & $1970-1974$ & Las cuatro estrategias \\
\hline Alfonso López & $1974-1978$ & Para cerrar la brecha \\
\hline Michelsen & & \\
\hline Julio César Turbay & $1978-1982$ & Plan de Integración Nacional \\
\hline Ayala & & \\
\hline Belisario Betancur & $1982-1986$ & Cambio con equidad \\
\hline Virgilio Barco & $1986-1990$ & Plan de economía social \\
\hline César Gaviria & 1990-1994 & La revolución Pacífica \\
\hline Ernesto Samper & 1994-1998 & El salto social \\
\hline Andrés Pastrana & $1998-2002$ & Cambio para construir la paz \\
\hline Álvaro Uribe Vélez & $2002-2006$ & Hacia un estado comunitario \\
\hline Álvaro Uribe Vélez & $2007-2010$ & $\begin{array}{l}\text { Estado Comunitario: desarrollo para } \\
\text { todos }\end{array}$ \\
\hline Juan Manuel Santos & 2010-2014 & Prosperidad para todos \\
\hline
\end{tabular}

En 1950, la Educación Primaria, regularmente, tenía un horario de 8 a.m a 11 a.m y en la tarde de 1 p.m a 4 p.m; se laboraba de lunes a sábado (este día solo media jornada). Un alumno en este curso debia estudiar entre 12 a 15 asignaturas, entre otros ahorros, granja escolar, la urbanidad de Carreño. Esta era considerada como la jornada ordinaria, recomendable por ser más pedagógica. El calendario $A$, iba de Febrero a noviembre; existian vacaciones intermedias entre Junio y Julio y al final del año desde Noviembre hasta Enero. Se realizaban exámenes a mitad y fin de año, las calificaciones estaban en una escala de 1 a 5 .
En la educación secundaria se estudiaba en jornada ordinaria de 8 a.m a 12 a.m y en la tarde de 2 p.m a 5 p.m, de lunes a sábado, el miércoles por la tarde era tarde deportiva y el día sábado era media jornada.

Los gobiernos, años más adelante, establecen la comúnmente doble jornada, de 6:30 a.m a 12:30 p.m y en la tarde de $12: 30$ p.m a 6:30 p.m; se cambia el término de asignatura por el de área; se implementa la TV educativa en los campos para enseñar a los niños a través de guías; se establece la oficina de OAPEC, adscrita al Ministerio de Educación Nacional, y en cada una de las secretarias de los 
departamentos era la encargada de : a)Distribuir unas guías didácticas para el Magisterio rural. b) control de la enseñanza a través de la televisión para los niños del campo) oficina también responsable de la entrega, mantenimiento y supervisión, del Programa de Educación para los niños del sector rural. Esta experiencia fue un fracaso.

Llega la implementación de la escuela unitaria que dejó muchas dudas sobre su eficiencia. Ante la escases de docentes (años 1965-19661967) el gobierno aprovechando el recurso de los bachilleres que habian sido aplazados para definición del pago del servicio militar obligatorio, establece que estos bachilleres en su condición de soldados debían prestar su servicio con un tiempo compartido entre enseñar en una escuela y la otra parte en los batallones cumpliendo con el servicio militar. Esto se denominó Plan ANDES, el que igualmente fue un fracaso.

Hacia 1963, en las escuelas de Educación Primaria, ya con el concepto de áreas (evaluación cada bimestre) se adopta en la parte evaluativa un sistema educativo denominado "ley de arrastre". Mediante el cual el estudiante salía favorecido cuando al promediársele las cinco notas obtenidas, en un área si le daban dos o tres centésimas es decir que superaban los 2,5 automáticamente al estudiante habia que colocársele una nota de 3 , ganando asi el área; así se empleaba para las demás áreas, lo cual si bien el estudiante era favorecido, el procedimiento generaba pereza lo cual repercutía en la calidad de la educación.

Durante varios años las escuelas normales y las facultades de educación sufrieron serias reformas en sus planes de estudios. Hoy en día con base en el decreto 1278 de Junio 19 del 2002 firmados por el presidente de ese entonces Dr. Andrés Pastrana Arango y el Dr. Francisco José Lloreda Mera, tanto las escuelas normales como las facultades de educación han perdido su real identidad porque están en una fase de desaparición.

El gobierno a nivel nacional, regional y local, han autorizado la apertura de una infinidad de establecimientos educativos, en diferentes modalidades, privados otorgándoles personería jurídica, licencia de iniciación de labores y luego licencia de aprobación de estudios con fines financieros y de explotación a las clases populares.

Aparecen normas autorizando validaciones de bachillerato en un año, donde los aspirantes compran un formulario en uno de las entidades bancarias, para presentar unas pruebas y llegar a obtener el título de bachiller.

Existen establecimientos ofreciendo programas para lograr el título de bachiller en solo 3 años; estudiando los viernes y sábados para aprobar 2 años y así sucesivamente. Esto es ilógico y también injustificable porque cuando un estudiante con sacrificio estudia pierde y repite un año en unos establecimientos aprobado oficialmente, podrá tardarse para graduarse de bachiller 6 o 7 años; mientrasque uno de los estudiantes que pagan en una institución podrá validar 2 años en uno y asi graduarse en solo 3 años.

El gobierno crea organismos cuyo objetivo es abrir créditos financieros a los estudiantes como ICETEX y ciertos fondos prestamistas.

Se adoptaron innovaciones extranjeras, que en sus países de orígenes ya habian sido revaluadas. Como: la creación de los institutos de enseñanza media diversificada INEM; los cuales en el gobierno del Dr. Misael Pastrana Borrero se construyeron los primeros INEM de un total de 19 que se tenían previstos; aparecen las concentraciones de desarrollo rural; los centros experimentales pilotos (CEP); los centros auxiliares de servicios docentes( CASD). 
Hace eco, en los planes de desarrollo educativo los planes de emergencia que aún persisten. Como las dobles jornadas, el aumento escandaloso de alumnos por curso, sin tener en cuenta la capacidad locativa, lo cual va en detrimento de la buena calidad de la educación que debe prestarse.

Perdura la injustificada discriminación entre la educación que se imparte en los campos con referencia a la ofrecida en las ciudades.

El sistema educativo colombiano existe mediante normas. Pero la realidad objetiva es lo que se observa dentro del panorama nacional. Asi tenemos:

De mil niños que están en edad escolar y que inician su primero de primaria terminan grado quinto 250.

De esos 250 que pasan a la educación secundaria solo se gradúan 25 como bachilleres.

$Y$ de esos 25 que comienzan carreras profesionales solo se graduarán dos o tres.

Conclusión: solo un $0,3 \%$ de esos mil que iniciaron primero de primaria logran ser profesionales.

Actualmente, año 2012 (siglo XXI) continua siendo latente el problema de la deserción escolar, el cual viene represado desde hace muchos años atrás.

La política del actual gobierno del Dr. Juan Manuel Santos sobre gratuidad de la educación pública solo es una farsa que tiende hacia la privatización de la educación pública, pues obedece a politicas ordenadas por el fondo monetario Internacional dentro del modelo económico neo liberal y las políticas de globalización.

\section{4) Breves conceptos relacionados con} planes educativos realizados por algunos mandatarios nacionales

En el siglo XX hubo intento en algunos gobiernos por hacer de la educación pública una fortaleza para el desarrollo nacional. Puede mencionarse el caso del Dr. Alfonso López Pumarejo, quien independizándose de los ordenamientos del concordato le dió a la educación pública un buen respaldo económico y cultural. A la universidad Nacional, la dotó de una infraestructura para hacer de ella la "CIUDAD BLANCA", propiciando la creación de nuevos programas académicos, creando estímulos económicos para los docentes, autorizando la contratación de investigadores destacados en el exterior para conformar grupos investigativos de alta calidad en la Universidad Nacional.

El Dr. Jorge Eliécer Gaitán, en 1946, siendo Ministro de Instrucción Pública y Salud, presento un importante proyecto sobre nacionalización de la educación, el cual comprendía:

- Establecimiento de restaurantes escolares.

- Uniformes.

. dotación de bibliotecas.

- Servicios de salud y bienestar estudiantil.

- Estímulos económicos. Mejorar los salarios para los educadores y garantizar su estabilidad.

- Creación de nuevos establecimientos educativos.

- Responsabilidad presupuestal para todo los planteles educativos por cuenta del Estado.

. Otorgamiento de becas.

Infortunadamente las aspiraciones del Dr. Gaitán y el Dr. López Pumarejo se vieron frustradas ante la posición pesimista del congreso de la república quien en últimas negó el proyecto.

Desde 1946 a 1957 la educación, gracias al concordato es fuertemente influenciada por las directrices eclesiásticas se impone una 
educación memorística tradicional y el clero católico entra al dominio en las diferentes áreas del conocimiento. Así se puede observar en los pensum oficiales donde inclusive los textos didácticos eran impresos y comercializados por comunidades religiosas de trayectoria en Colombia, caso: los Jesuitas, los hermanos Maristas, la Salle, Franciscanos, La Presentación, las Bethlemitas, las Marillacs, etc.

En el gobierno del general Gustavo Rojas Pinilla quien bajo el lema "Paz, Justicia y Libertad" se acentúa el poder religioso con el poder castrense. No fue raro que la Universidad Nacional de Colombia en Bogotá tuviese un militar como rector.

A partir de 1958 hasta el año 1974 donde figuró un gobierno alternativo que se conoció con el nombre del Frente Nacional donde los 16 años que duro dicho frente fue gobernado 4 años por Liberales y 4 años por conservadores hasta cuadrar los 16 la educación Colombiana vuelve a sufrir una influencia Norteamericana; porque los gobiernos de Estados Unidos bajo la administración del Dr. John FitzGerald Kennedy con su programa "ALIANZA PARA EL PROGRESO" logra imponer sus criterios en casi todos los gobiernos de esa época en América Latina.

En el año 1960 llega a Colombia el gringo Rudolph Atcon con la misión de elaborar un diagnóstico para detectar la problemática en las Universidades Públicas y reducir el grado de rebeldia e inconformismo expresado por el movimiento estudiantil, de los profesores y de las clases pobres.

4.1) Algunos hechos sobresalientes en las administraciones presidenciales a nivel educativo

De 1970 a 1974 el presidente Misael pastrana Borrero, nombra como Ministro de Educación al Dr. Luis Carlos Galán, (considerado como el ministro más joven, a los 27 años de edad) sin embargo le correspondió afrontar una dura huelga del magisterio Nacional, liderada por el presidente de FECODE, en ese entonces el maestro Adalberto Carvajal. Huelga que terminó con la remoción del Ministro de Educación y se logró vencer con el derrocamiento de un estatuto docente lesivo, retrograda y antipedagógico. En la administración Pastrana se proyectaron la creación de los INEM, la implementación de la escuela unitaria.

Durante el gobierno del Dr. Alfonso López Michelsen (1974-1978) se divulgo la ley 43 de diciembre 11 de 1975, siendo Ministro de Educación el señor Hernando Duran Dussan (ex ganadero, político de turno que posteriormente ocupara la Alcaldía de Bogotá.) Dicha ley fue conocida como "nacionalización de la educación"; la cual fue todo lo contrario de la esencia de una nacionalización y se redujo su finalidad a un marcado centralismo de poder y autocracia llegando el ejecutivo a tomar el manejo administrativo y financiero de los departamentos. Violando la autonomía de las seccionales regionales sobre todo en materia educativa. En la administración del Dr. Julio Cesar Turbay Ayala (1978-1982), caracterizada por el alto grado de represión y persecución popular, el magisterio logra a base de una lucha planificada obtener que el gobierno expidiera el decreto 2277 de septiembre 14 de 1979 donde se configura una carrera docente acorde a los intereses de la educación. Es de resaltar el papel desempeñado en ese entonces por su ministro de educación, el vallecaucano conservador Dr. Rodrigo Lloreda Caicedo; quien después de varias secciones con delegados del gobierno y de la Federación Colombiana de Educadores FECODE, obtuvieron este estatuto, muy diferenciado este estatuto al expedido en la administración del Dr. Andrés Pastrana Arango (1998-2002), quien con su decreto 2278 del 19 de Junio del 2002 apoyado con la firma del Ministro de Educación en ese entonces Dr. Francisco José Lloreda Mera ha sido el decreto 
más violatorio a las aspiraciones del magisterio. Con ese estatuto se golpeó duramente a los fines y propósitos de las escuelas normales y de las mismas facultades de Educación.

Es algo paradójico que cuando el Dr. Lloreda Caicedo siendo Ministro de Educación posiciono al maestro, a las escuelas normales y las facultades de Educación, en sitio preferencial su hijo Francisco José Lloreda Mera haya sido capaz de tirar por el suelo la tarea meritoria de su señor padre.

En el periodo 1982-1986 gobierna al país el ciudadano de Amagá (Antioquia) Dr. Belisario Betancourt quien en su gobierno hizo demostración de un populismo exagerado. Continuo con la rutina educativa del gobierno anterior y reprodujo de manera muy regular el modelo de educación abierta y a distancia; casi un plagio de lo que él había observado en España cuando fue embajador en dicho país. Implemento por una orden externa la denominada "promoción automática" y hoy en día cuando se exige la acreditación de los establecimientos públicos educativos figura como uno de los máximos representantes de la multinacional Santillana, que es la responsable de hacer los procesos de acreditación en Colombia.

Tuvo como ministros de educación a los Drs. Jaime Arias y Antonio Yepes.

El Dr. Virgilio Barco Vargas, durante su gobierno de 1986 a 1990 continúa con los parámetros educativos ya establecidos en los gobiernos anteriores.

El Dr. Cesar Gaviria en su mandato 1990-1994 ocurren estos hechos significativos:

El pueblo designa una asamblea nacional constituyente para elaborar la carta magna de Colombia en el año de 1991; acabando así con la constitución de 1886 que requería ser derogada.
El 8 de febrero de 1994 con la firma de la Ministra de Educación de ese entonces Maruja Pachón de Villamizar publica la ley 115 , conocida comúnmente como la ley General de Educación, la cual constituye un tratado amplio en el campo educacional dándose especial importancia a la comunidad en la elaboración del proyecto Educativo Institucional PEI y de otros proyectos.

* Designo una comisión de altos científicos que en el argot popular se llamaba la comisión de los sabios. Esa comisión estaba integrada por Carlos Eduardo Vasco, Eduardo Aldana Valdez, Luis Fernando Chaparro Osorio, Gabriel García Márquez, Rodrigo Gutiérrez Duque Rodolfo Llinas, Marco Palacio Rozo, Manuel Elkin Patarroyo, Eduardo Posada Flórez y Ángela Restrepo Moreno, ellos plasmaron en un documento titulado: "Colombia: al filo de la oportunidad" el diagnostico, el estado actual, la proyección de la educación y las alternativas viables de solución. El gobierno del Dr. Gaviria adquirió el compromiso de ponerlo en ejecución, cosa que nunca se hizo.

En el plan de desarrollo del Dr. Ernesto Samper "El salto social" en el periodo 1994-1998, se redujo a actividades simples de rutina a nivel educativo.

El Gobierno del Dr. Andrés Pastrana (19982002) denominado "Cambio para construir la paz" fue muy espurio en el terreno educacional. En los 8 años del mandato del Dr. Álvaro Uribe Vélez denominados sus planes de gobierno "hacia un estado comunitario" y "estado comunitario: desarrollo para todos" quedaron a la expectativa de obras concretas para la educación. Mucho se habló sobre la cobertura, la eficiencia, la eficacia y la calidad de la educación. El presupuesto para la educación fue muy inferior a las expectativas trazadas en el plan de desarrollo.

En nuestras escuelas y colegios, y aún en la universidad se quedaron muchos estudiantes 
fuera del sistema escolar, se aumentó la discreción. El hacinamiento de los estudiantes en las aulas escolares fue un indicador de los planes de emergencia generados por el gobierno del Dr. Uribe.

El Dr. Juan Manuel Santos elegido como presidente de la república en el periodo 20102014 ha venido impulsando su plan "prosperidad para todos". Pero la gran realidad es que en tan solo un año ha fracasado con su famosa reforma a la ley 30 de 1992. La famosa gratuidad ha sido toda una fantasia que en un futuro conducirá hacia una marcada privatización de la educación pública.

\section{2) Ejemplo educativo de Cuba para la América Latina}

En el año 1959, en Enero un ejército integrado por 100 soldados bajo los mandos de los comandantes: Ernesto "Che" Guevara, Camilo Cienfuegos, los hermanos Fidel y Raúl Castro Roux, y otros dan un fuerte golpe al derrocar del poder cubano al dictador Fulgencio Batista, súbdito de los gobiernos gringos de los E.E.U.U quienes con sus oligarcas hacían destrozos a la tierra caribeña. El analfabetismo, superaba los $80 \%$; pululaban los juegos de azar, los casinos; la prostitución era implementada por los gringos; el desempleo y la inseguridad eran indicadores claros que mostraban un atraso bien relevante.

Con el triunfo de la revolución cubana, sus dirigentes empezaron a la elaboración de un plan de desarrollo de corte socialista, tomando como base un diagnostico hecho de manera participativa con todas las comunidades en forma ascendente, es decir, desde los sectores de base hacia arriba; estableciendo las prioridades en cuanto a sus necesidades y acorde a las mismas capacidades.

Resultados de este diagnóstico fueron los planes para el sector educativo a corto mediano y largo plazo para obtener la meta de reducir el alto grado de analfabetismo a un indicador que sirviera de ejemplo para los demás países, hoy solo se tiene un 5 a $6 \%$ de analfabetismo, que constituye uno de los indicadores más bajos en la América Latina.

Paralelamente se elabora un plan agrario, llevándose a cabo una efectiva reforma agraria para parcelar los terrenos que habian expropiado a los terratenientes y dar a cada habitante su porción de tierra para trabajar.

En el campo de la salud el plan elaborado llevo a ubicar la medicina al alcance de todos los cubanos y obtener los mejores equipos para brindar mejores servicios médicos con extensión a otras naciones.

En el plan de vivienda se logró a corto plazo que cada familia tuviera su propia vivienda y su alimentación fuera subsidiada.

Se ha dado un impulso a la cultura y el respeto hacia la soberanía nacional.

El régimen socialista se ha caracterizado por erradicar la corrupción; fomentar la convivencia pacífica y el espíritu de solidaridad.

El bloqueo económico que los gobiernos de E.E.U.U han realizado al régimen cubano ha sido factor negativo para un mejor desarrollo de Cuba.

En la industria sobresale como productos principales la caña de azúcar y el tabaco.

El folclore es altamente difundido desde la escuela.

Para los goblernos de los E.E.U.U. En la década de los sesenta, surgió de manera preocupante contemplar y estudiar los impacto del fomento revolucionario cubano y su preocupación de la factibilidad que este podia extenderse hacia 
otros países de América Latina especialmente Colombia, Venezuela y Bolivia.

Esto lleva entonces a las autoridades gringas en el año 1959 a convocar a una reunión extraordinaria a los representantes de los gobiernos de centro y Suramérica, en especial a los ministros de hacienda y Educación, para tratar en Punta Del Este (Uruguay) lo relacionado con las consecuencias que la revolución traería a sus respectivos países.

En esa reunión examinaron el porqué del desarrollo en los diferentes campos estaba alcanzando Cuba. Concluyendo en la necesidad, a manera de plagio, de crear las oficinas de planeación (donde no existieran) y de fortalecer las ya existentes. Es así como en el caso de Colombia esta oficina empieza a fortalecerse y los gobiernos le dan funciones especiales hasta llegar a constituirse un SUPERMINISTERIO con influencia y decisión al igual que las otorgadas al Ministerio de Hacienda y con el respaldo del presidente de la república.

Pero no han podido igualar a la experiencia cubana.

\section{Conclusiones}

\section{A) Generales}

" La recepción de las recomendaciones hechas por las misiones internacionales por parte del Estado y de los gremios es bastante positiva. Si se tiene en cuenta que uno de los principales objetivos era lograr un manejo técnico de los asuntos económicos y acceder a la modernización institucional, de tal manera que el país encontrara la ruta al desarrolio, se aprecia la identificación de los intereses nacionales con las propuestas hechas por los consejeros externos.

- Al revisar la experiencia de los años treinta se observa que los planteamientos centrales sobre manejo monetario y equilibrio fiscal son compartidos tanto por las autoridades gubernamentales como por los empresarios. Son reiteradas las alusiones a la necesidad de mantener el control de los medios de pago y del gasto público. Más aún, la función de los consejeros es hacer los proyectos de Ley necesarios para la implementación de sus recomendaciones.

En los años cincuenta, al igual que en el contexto internacional, en Colombia hay pronunciamientos en torno a la importancia de profundizar el proceso sustitutivo de importaciones, a la vez que elevar el nivel de vida de la población. Una clara evidencia de ello es el informe elaborado en 1939 por el equipo del Departamento Económico de la Cancillería, dirigido por Luís Eduardo Nieto Arteta y Guillermo Torres Garcia, en el que se hace una reflexión sobre la manera como el Estado debia participar en la orientación de la economía nacional y enfrentar las adversas condiciones que le impondría al país el conflicto internacional. En ese documento se sostenía que la población colombiana estaba

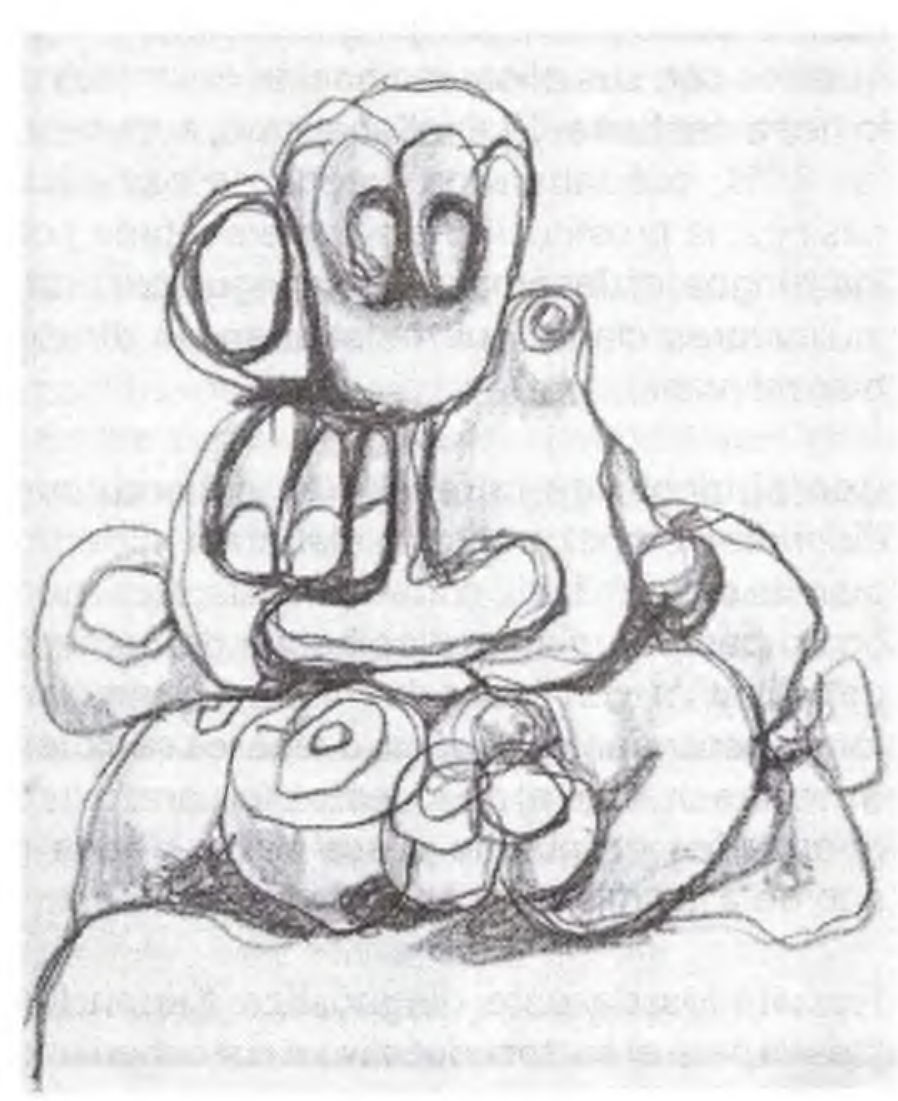


en condiciones de subconsumo, es decir, no lograba satisfacer las necesidades básicas. Para revertir esta situación era preciso estimular la producción bajo la estrategia de sustitución de importaciones, en la que el crecimiento económico se hiciera a través del mercado interno y con una fuerte intervención del Estado.

De otra parte, el Comité de Desarrollo que evaluó el informe Currie con miras a realizar los proyectos de ley pertinentes, se muestra de acuerdo con la orientación general del informe y con muchas de sus propuestas particulares. Por su parte, la Misión de CEPAL en 1954, es bastante técnica y su propósito era establecer el vínculo entre las autoridades económicas y los adelantos en programación macroeconómica. El informe de CEPAL presentado en 1960 fue realizado contando con una activa participación de funcionarios colombianos $y$, al igual que la de 1954, tenía un gran componente educativo.

Igualmente, en el país no se pone en duda la importancia de transformar la administración pública para hacer de ella un instrumento eficaz dentro de la política económica. EI establecimiento de la carrera administrativa, que limpie la contratación pública de factores políticos, hace parte del sentimiento nacional, pero no de la práctica. La urgencia de mejorar la calificación y el salario de los funcionarios públicos, es un requisito esgrimido por muchos para lograr que el Estado compita con el sector privado por igual calidad de la fuerza de trabajo. Durante muchos años y muchas reformas se discutieron estos temas y a su clarificación contribuyeron de manera significativa las misiones extranjeras desde los años treinta; sin embargo, su puesta en marcha es gradual e incompleta, al menos hasta la reforma administrativa de 1968 promulgada en la administración de Lleras Restrepo.
Dos puntos importantes de discrepancia que tienen que ver con las sugerencias de las misiones son: la reformas en el sector agrícola y los cambios impositivos.

Un primer debate sobre la reforma se lleva a cabo a raíz de la propuesta hecha por Currie en torno a estimular la producción agrícola por medio de la imposición a las tierras improductivas. El segundo se desarrolló a partir de 1958, luego del informe de la misión Lebret y de las reuniones internacionales. La prensa y buena parte de las revistas especializadas apoyaron los planes de reforma agraria, aun cuando muchos autores llamaron la atención sobre la necesidad de adelantar estudios que dieran cuenta de las circunstancias en las que se desenvolvía el sector agrícola.

Por su parte, la SAC consideraba que la propuesta de tributación en el sector agrícola era de marcada orientación socialista; esta agremiación afirmaba que "pretender que hay una oligarquia latifundista en Colombia y que por esto se ha de socializar el problema de la tierra es una necedad o ignorancia de la realidad del pais o quizá simple demagogia".34 La solución según este grupo estaba en adelantar un gran plan de colonización y parcelación técnicamente estudiado. De acuerdo con Bejarano, la SAC adelantó una verdadera campaña contra la propuesta de Currie, hasta convencer al Ministerio de Agricultura y Ganadería de que la objetara; finalmente, el proyecto de gravar las tierras improductivas fue archivado. Opiniones similares fueron esgrimidas en torno a la reforma agraria de 1961; en particular, son desfavorables las relativas a la acción del Incora.

Sobre el tema tributario es preciso destacar dos importantes capítulos, el primero correspondiente a las recomendaciones de la Misión Currie y el segundo a la reforma 
impositiva de 1960, elaborada durante la permanencia de la Misión CEPAL.

De acuerdo con Currie, si el Estado quería incrementar el gasto público en infraestructura para impulsar la inversión privada, era necesario aumentar su capacidad de recaudo. En esa dirección se hacía indispensable ajustar la estructura impositiva desplazando la carga tributaria de las sociedades hacia las personas naturales, esta estrategia se apoyaba en la idea de que un impuesto a las empresas afectaba la disponibilidad de fondos y por ello la inversión.

Para realizar el traspaso del esfuerzo tributario, se sugería la aplicación del gravamen de renta a los dividendos, en razón a que ellos representaban utilidades constitutivas de capacidad tributaria; también se propone la disminución de las tarifas progresivas del impuesto de renta a las sociedades, las cuales soportaban los mismos incrementos que las de las personas naturales y, finalmente, la simplificación del sistema tributario.

Con la reforma de 1953, adoptada durante el gobierno de Rojas Pinilla y al amparo del artículo 121 de la Constitución de 1886, se logra una reducción de la tarifa progresiva para las sociedades anónimas y el establecimiento del gravamen a los dividendos.

Respecto al impuesto sobre los dividendos liquidado en cabeza de quien los recibe-, la Ley cierra un primer gran ciclo de debates que el país había sostenido durante varios años; aun cuando se convirtió en un punto recurrente en todas las reformas tributarias posteriores. La primera tentativa de hacer esta imposición fue en 1942, pero no tuvo acogida; posteriormente en 1946 el gobierno insiste en su implementación, pero suscitó la protesta de la Andi y fue postergada; en 1948 un Comité de expertos financieros se inclinó por este gravamen, pero en su momento tampoco fue aplicado.

- Por su parte, la reforma tributaria de 1960 respondió a las necesidades de impulsar la inversión privada sustitutiva de importaciones por medio de las exenciones tributarias a las industrias básicas. Esta reforma recogió buena parte de los planteamientos hechos desde la misión Currie y las recomendaciones aportadas por otras misiones que abordaron específicamente el tema impositivo. El proyecto fue evaluado por una misión de técnicos de la Universidad de Harvard y, además, fue presentado en la Conferencia sobre Administración Tributaria (1961) dentro del Programa Conjunto de Tributación creado por la OEA, el BID y la CEPAL, orientado a la conformación de un sistema fiscal que cumpliera los objetivos del crecimiento económico-, en la cual fue destacada como pionera en el nuevo enfoque.

A diferencia de las anteriores reformas, la de 1960 tuvo un amplio debate. El ponente del proyecto, Luis Guillermo Echeverri, organizó un seminario de estudios sobre el régimen tributario, en el cual participaron voceros de los gremios económicos, de diversas organizaciones científicas, sindicales, profesionales y administrativas, y algunos particulares especializados en la materia. Entre las principales críticas al proyecto presentado en 1959 estaba el no cubrir los aspectos sociales y de fomento económico. Con esta base y teniendo en cuenta las recomendaciones de la CEPAL y de la Misión de Harvard, la reforma incluyó un plan de exención de impuestos de renta a todas las industrias básicas y complementarias de la producción de hierro indispensables en la ejecución de 
programas de desarrollo; también, aunque timidamente, la reforma propone aumentar los ingresos destinados a la asistencia pública con los recursos provenientes del recargo al predial sobre las residencias de lujo, las ganancias ocasionales y los gravámenes a las inversiones y consumos suntuarios.

Quizás los desacuerdos más fuertes se generaron en las medidas de política económica adoptadas para lograr la estabilización macroeconómica. No obstante, éstas no forman parte del diagnóstico y las recomendaciones hechas por los consejeros externos, pero se formulan como la base para adelantar la recuperación o el crecimiento económico.

\section{B) Especificas}

Sobre planes de desarrollo del sector educativo en Colombia:

la oficina de planeación nacional se ha constituido en un SUPERMINISTERIO que centraliza toda una serie de acciones, junto con el Ministerio de Hacienda y la presidencia de la República.

Los planes de Desarrollo del sector educativo son elaborados de una manera verticalista, muchas veces sin el conocimiento y participación de los bases, de las personas que realmente conocen la problemática educativa en su medio.

Los funcionarios designados para desempeñar los cargos de responsabilidades como Ministros(as) de Educación, secretarios(as) Departamentales y secretarios(as) Municipales de Educación son en los términos populares fichas politiqueras, que poco o nada conocen de Educación, lo cual trae como consecuencia la degradación en el campo educativo.
- En varias ocasiones los planes de desarrollo gubernamentales y del sector educativo chocan con lo ambicioso, lo superficial y la imposibilidad de ser realizados dentro del tiempo y metas propuestas.

- La educación en Colombia desde tiempos memorables no ha recibido un presupuesto adecuado, amplio que le permita a sus diferentes agentes, plasmar en realidades proyectos que conduzcan hacia una calidad de la educación, con extensión a todas las clases de la comunidad Colombiana.

Es el sector educativo donde la improvisación en imponer políticas experimentos en un sentido autoritario los planes educativos tienden a constituirse en planes de emergencia; con una durabilidad y lógica; puesto que si son planes de emergencia debieran ser pasajeros.

Bibliografía

Álvarez, A. (1951).memoria de hacienda y crédito público 1951, Bogotá: imprenta del Banco de la República.

Bejarano, J.A (1974). "Currie: diagnóstico y estrategias", en ensayos de interpretación de la economía Colombiana, Bogotá, Editorial la carreta.

Bejarano, J.A (1974). "La economía Colombiana desde 1950", en ensayos de interpretación de la economía Colombiana, Bogotá, Editorial la carreta.

Currie, L. (1951). Bases de un programa de fomento para Colombia, Bogotá, ediciones del banco de la república.

Currie,L. (1961). Operación Colombiana, Bogotá, biblioteca de estudios económicos, 